\title{
Smoking and death in Russia
}

Improvements in public health can be obtained by eliminating or reducing relatively minor risks which are more or less prevalent in populations. Much larger gains might be possible through even modest reductions of large hazards such as tobacco use. Policies and programmes to reduce tobacco consumption are more likely to be implemented and more likely to be effective if there is direct, disaggregated, and recent local evidence on the extent of tobacco use and its harms. Such evidence might usefully describe several indicators of the tobacco epidemic including the patterns of tobacco consumption by various sectors of the population, how these are changing, the extent of disease caused by tobacco (and how this is changing), as well as the economic costs of tobacco use, direct and indirect.

Public policy responses and advocacy must be based on detailed, reliable information about tobacco use and the extent of diseases caused by it. Just as crude prevalence or consumption figures are not helpful in focusing policy responses, indirect estimates of tobacco-attributable mortality are inadequate in populations where there are high background risks for major diseases caused by smoking. This is likely to be the case in Russia where recorded vascular disease mortality among men is among the highest in the world, and is a principal cause of their extraordinary risk of death, particularly in middle age. ${ }^{1}$ Estimates for 1990 suggest that a man in Russia who reaches the age of 35 has a $52 \%$ chance of dying before age 70 , similar to the risk estimated for sub-Saharan Africa, and substantially higher than the average risk of death (30\%) among middle-aged men in Western countries. ${ }^{23}$

Indirect estimates of mortality from smoking suggest that much of this excess male mortality in middle age is attributable to the effects of past smoking among Russian men. Figure 1 compares the risk of death (at 1990 rates) among middle-aged men (and women) in the United States with those in Russia. Not only are the background hazards (not attributable to smoking) greater in Russian men $(30 \%)$ than in American men (20\%), but specifically, the risk of dying in middle age from tobacco is substantially

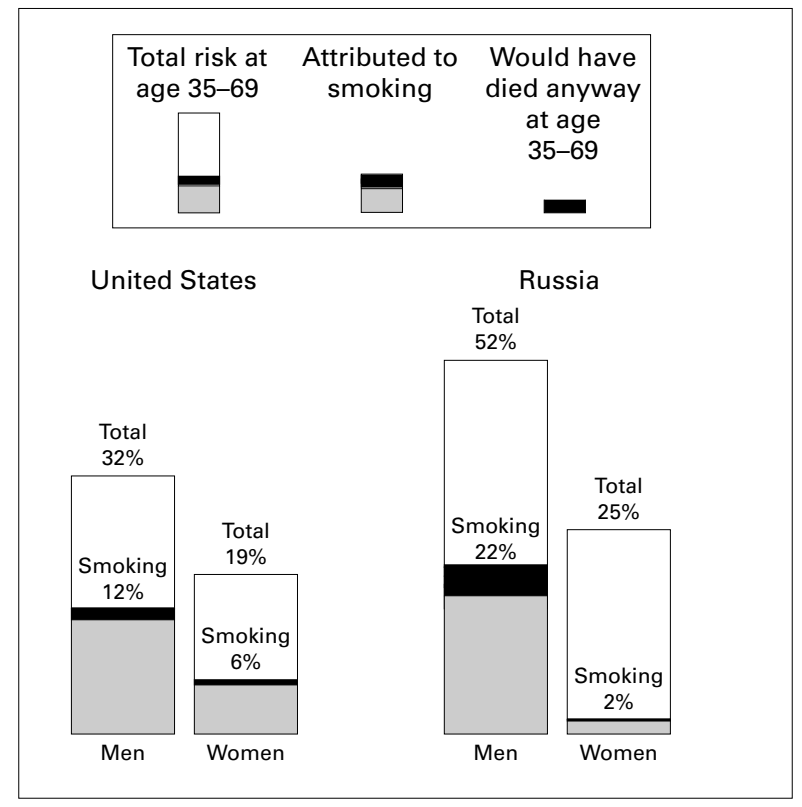

Short caption please. greater for men in Russia (22\%) than for men in the United States (12\%).

These individual risks imply a large annual mortality from tobacco. Some 250000 men are estimated to have died in Russia in 1995 due to tobacco use, three out of four of them (190 000) at ages 35-69 years. ${ }^{2}$ Smoking control alone would likely have a significant impact on reducing premature male mortality in Russia.

For women, factors other than tobacco are primarily responsible for the higher premature mortality in Russia (25\%) compared with the United States (19\%). However, the absolute risk of death in middle age attributed to smoking is three times higher in American women (6\%) than in Russian women (2\%), reflecting longer smoking histories in the United States, at least among females. Deaths from smoking among women in Russia are still comparatively few and a further exacerbation of the public health disaster caused by tobacco in Russia could still be avoided if smoking levels in women can be contained.

But can they? Previously, comprehensive, nationally representative data on smoking patterns in Russia were not readily available but, in view of the indirect mortality numbers, smoking among men is probably very common, and had been for several decades. The careful, detailed analysis by McKee and colleagues in this issue of Tobacco Control ${ }^{4}$ confirms that this is indeed the case and suggests that smoking-attributable mortality, among men at least, is likely to persist at these appalling levels given that about two-thirds of young and middle-aged Russian men currently smoke. What is also alarming from their findings is the clear age gradient in female smoking prevalence with close to $30 \%$ of young adult women being regular smokers, compared with $5 \%$ at older ages (55 and over). Currently, lung cancer and other diseases caused by smoking are comparatively low in Russian women (who by and large have never smoked), but these rates can be expected to rise rapidly in the future if these younger women continue to smoke into middle and old age.

The analysis by McKee and colleagues is important because it helps explain why tobacco is such a large hazard among Russian men; it describes which groups of men in particular are most at risk, and provides an urgent basis for action to reduce tobacco consumption in Russia, not only in men, but increasingly in women. Such action is likely to be accelerated if direct evidence on the size of the tobacco hazard in Russia could be assembled. A large-scale retrospective study, perhaps using novel techniques as have been applied in China by Liu and colleagues, ${ }^{5}$ would provide such evidence and at the same time quantify the contribution of other causes, such as alcohol, to the dramatic reversal in Russian survival patterns that has been observed since the late 1980s. The 6-7 year decline in Russian male life expectancy since 1987 represents one of the major public health disasters of the 20th century, yet little is reliably known about its causes, including what might have been the role of tobacco. ${ }^{6}$ By including a single question on smoking status on the death certificate, as has now been done in South Africa (written communication from Freddy Sitas, National Cancer Registry, Johannesburg, South Africa, 21 August 1997), and perhaps one on alcohol (vodka) consumption as well, causal attribution can be adequately assessed.

Comparative studies suggest that the appalling levels of smoking-attributable mortality reported for Russian men are not uncommon in other countries of central and 
eastern Europe. The estimate of $30 \%$ of all male deaths in Russia (and $42 \%$ in middle age - that is, 35-69 years) is similar to the levels estimated for Poland, Hungary, and the Ukraine. ${ }^{2}$ Approximately one in two cancer deaths in men in these countries is attributable to smoking. ${ }^{78}$ What further increase in tobacco hazards will occur as a result of changes in cigarette sales and promotion following the political changes that have taken place in the region since the late 1980 s is difficult to predict. Indeed, it is probably unnecessary to do so. Enough is already known about the extent of the tobacco epidemic in the region to demand urgent and sustained action to reduce tobacco use.

The World Health Organisation continues to provide direct assistance to many central and eastern European countries to prepare and implement national tobacco control programmes. Some notable successes have already been achieved. For example, Slovenia has implemented comprehensive tobacco control measures, including a ban on tobacco advertising. Poland has a partial ban on tobacco advertising and strong, prominent warnings on cigarette packages and tobacco billboards, one of the few forms of tobacco advertising still permitted.

But more action is required. Real progress in slowing the epidemic will only be achieved if urgent, effective, and comprehensive action is taken by all countries in the region, including, and perhaps most urgently, in the largest one, the Russian Federation.

The comments of Neil Collishaw and Richard Peto are gratefully acknowledged.

Programme on Substance Abuse,

ALAN D LOPEZ

World Health Organisation,

1211 Geneva 27,

Switzerland.

lopeza@who.ch

1 World Health Organisation. World health statistics annual. Geneva, World Health Organisation, 1996 and previous years.

2 Peto R, Lopez AD, Boreham J, et al. Mortality from smoking in developed countries, 1950-2000. Oxford, Oxford University Press, 1994.

3 Murray CJL, Lopez AD. Mortality by cause for eight regions of the world: Global Burden of Disease Study. Lancet 1997;349:1269-76.

4 McKee M, Bobak M, Rose R, et al. Patterns of smoking in Russia. Tobacco Control 1998;7:22-6.

5 Liu B-Q, Peto R, Chen Z-M, et al. Tobacco hazards in China: proportional mortality study of one million deaths (submitted to BMF, February 1998).

6 Leon DA, Chenet I, Shkolnikov VM, et al. Huge variation in Russian mortality rates 1984-94: artefact, alcohol or what? Lancet 1997;350:383-8.

7 Doll R, Peto R, Lopez AD, et al. Tobacco and death in Eastern Europe. In: Bodner W, Zaridze D, eds. Cancer prevention in Europe. Geneva: International Union Against Cancer, 1993.

8 Lopez AD. Mortality from tobacco in the new independent states. In: Bobadilla JL, Castello CA, Mitchell F, eds. Premature death in the new independent states. Washington, DC: National Academy Press, 1997.

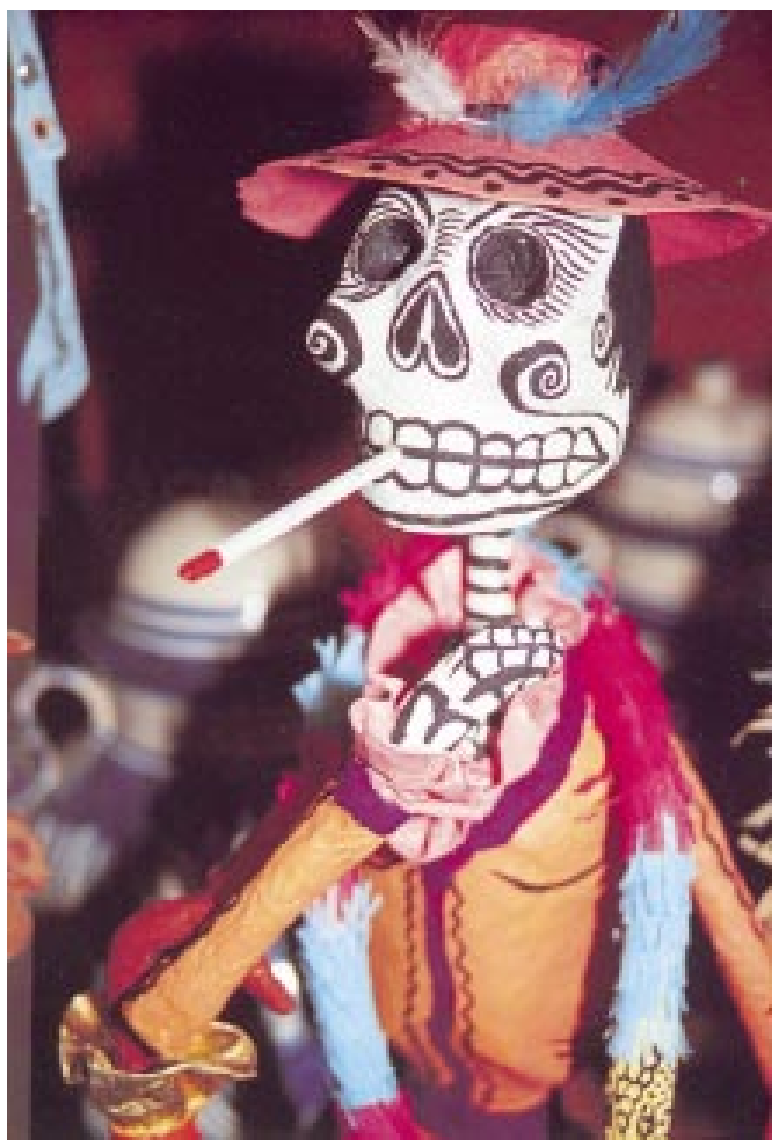

A postcard depicting "Dia de muertos" (Day of the Dead), celebrated in Mexico on 2 November. Submitted by Dr fudith Mackay. Photography by fürgen Bavoni. Design by $G$ Escobedo. 